This is a postprint version of the following published document:

Dios, M.; Kraleva, I.; González, Z.; Alvaredo, P.; Ferrari, B.; Gordo, E.; Bermejo, R. Mechanical characterization of $\mathrm{Ti}(\mathrm{C}, \mathrm{N})$-based cermets fabricated through different colloidal processing routes. Journal of Alloys and Compounds, 732, pp., 806-81, 25 January 2018.

DOI: https://doi.org/10.1016/i.jallcom.2017.10.274

(C) 2017 Published by Elsevier B.V. All rights reserved

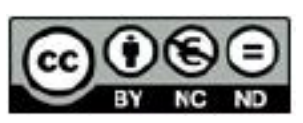

This work is licensed under a Creative Commons Attribution-NonCommercialNoDerivatives 4.0 International License. 


\title{
Mechanical characterization of Ti(C,N)-based cermets fabricated through different colloidal processing routes
}

\author{
M. Dios ${ }^{\text {a, * }}$, I. Kraleva ${ }^{\text {b }}$, Z. González ${ }^{\text {c }}$, P. Alvaredo ${ }^{\text {a }}$, B. Ferrari ${ }^{\text {c }}$, E. Gordo ${ }^{\text {a }}$, R. Bermejo ${ }^{\text {d }}$ \\ a Department of Materials Science and Engineering and Chemical Engineering, University Carlos III of Madrid, Avda. Universidad 30, 28911 Leganés, Madrid, \\ Spain \\ ${ }^{\mathrm{b}}$ Materials Center Leoben Forschung GmbH, Roseggerstrasse 12, 8700 Leoben, Austria \\ ${ }^{\mathrm{c}}$ Institute of Ceramic and Glass, CSIC, C/Kelsen 5, 28049 Madrid, Spain \\ ${ }^{\mathrm{d}}$ Institut für Struktur- und Funktionskeramik, Montanuniversitaet Leoben, Franz Josef Strasse 18, 8700 Leoben, Austria
}

In this work the influence of different colloidal processing routes on the mechanical behavior of several $\mathrm{Ti}(\mathrm{C}, \mathrm{N})$ based cermets has been studied. The materials were designed with a $\mathrm{Ti}(\mathrm{C}, \mathrm{N})$ content ranging between 80 and $85 \mathrm{vol} \%$, in a Fe Ni alloy matrix (with and without carbon addition). Three processing techniques were investigated: (i) Slip Casting (SC), (ii) Slip Casting + Cold Isostatic Pressing (SC +CIP), and (iii) Spray Dry + Uniaxial Pressing (SDP). Biaxial strength distributions were determined in all samples using the ball on three balls (B3B) method on disc shaped specimens. Results were interpreted in the framework of Weibull theory. The characteristic strength ranged between $1090 \mathrm{MPa}$ and $1870 \mathrm{MPa}$. A fractographic analysis performed on selected specimens showed different critical flaws, depending on the processing route, related to the composition and porosity level in each case. Single Edge V Notched Beam (SEVNB) specimens fabricated with SDP were tested under 4 point bending, in order to identify the effect of Fe Ni content and carbon addition on their fracture resistance. Detailed fractographic an alyses revealed slightly different mechanisms of fracture associated with the $\mathrm{Fe} \mathrm{Ni}$ and carbon content. Fracture toughness values ranging between $\sim 12$ and $\sim 14 \mathrm{MPa} \mathrm{m}{ }^{1 / 2}$ were measured. Based upon these findings the SDP route is proposed to improve both the strength and toughness of $\mathrm{Ti}(\mathrm{C}, \mathrm{N})$ cermets, which can be enhanced by the addition of carbon during the colloidal processing.

\section{Introduction}

Among the ceramic metal composite materials, titanium car bonitride based cermets have drawn great attention in an attempt to replace the traditional WC Co hardmetals. Notwithstanding their relatively lower bending strength as compared to hardmetals, $\mathrm{Ti}(\mathrm{C}, \mathrm{N})$ based cermets have an excellent and unique combination of physical properties such as high melting point, hardness at high temperature, wear and oxidation resistance and thermal conduc tivity $[1,2]$. All these characteristics make cermets well adapted to the requirements for high performance wear parts and semi finishing or finishing cutting tools. This fact offers the opportu nity to use relatively cheap and abundant raw materials, thereby reducing the dependence on critical raw materials such as W or Co.

\footnotetext{
* Corresponding author.

E-mail address: midiosp@ing.uc3m.es (M. Dios).
}

The mechanical properties of these composites are largely influenced by different parameters, such as the composition of the binder phase, the addition of secondary carbides, the size of the starting powders as well as the processing route.

In most $\mathrm{Ti}(\mathrm{C}, \mathrm{N})$ based cermets, the binder phase is mainly composed of $\mathrm{Ni}[3-8]$, Co [9,10] or a combination of both [11,12]. However, there is an interest to find alternative binder composi tions to replace them totally or partially, due to its classification as critical raw materials and the health risks. There are several studies that propose the use of Fe as a metal matrix for cermets [13-16], as it is non toxic and cheaper than the other routes as well as strengthened by heat treatment [17]. However, despite the considerable amount of research carried out, the application of such cermet systems is limited, mainly due to two major issues: The poor interfacial cohesion between the metallic phase and the ceramic particles [16] and the low toughness values resulting from the coarsening of the carbides. To overcome such limitations, the addition of alloying elements and compounds such as WC, $\mathrm{Mo}_{2} \mathrm{C}$, 
TaC, NiB, VC, Ta, C, Cr or Mo has been proposed [18-22], aiming to improve the wetting behavior between both phases during the liquid phase sintering as well as to hinder the ceramic particle growth. Xiong et al. [18] described the effect of WC, $\mathrm{Mo}_{2} \mathrm{C}$ and $\mathrm{TaC}$ additions on the microstructure and mechanical properties of ul trafine $\mathrm{Ti}(\mathrm{C}, \mathrm{N})$ cermets. The addition of $\mathrm{Mo}_{2} \mathrm{C}$ and $\mathrm{WC}$ improve the hardness and the strength, whereas $\mathrm{TaC}$ additions have a positive effect on the high temperature properties. However, an excessive addition was found to be detrimental for the mechanical properties of cermets. Guo et al. [17] reported the influence of the addition of $\mathrm{Mo}_{2} \mathrm{C}$ as secondary carbide to the composition of $\mathrm{Ti}(\mathrm{C}, \mathrm{N})$ Fe cer mets processed according to conventional powder metallurgy techniques. Although the $\mathrm{Mo}_{2} \mathrm{C}$ slightly affects the grain size due to the nature of the Fe binder, these cermets showed enhanced me chanical properties, including hardness ( 15 GPa) and transverse rupture strength (TRS) ( 1560 MPa). Naidoo et al. [7] found that the addition of Ta to $\mathrm{Ti}(\mathrm{C}, \mathrm{N})$ cermets can result in grain refinement and thus improving hardness (from $16 \mathrm{GPa}$ to $18 \mathrm{GPa}$ ) and fracture toughness (from 5.5 to $6.9 \mathrm{MPa} \mathrm{m}^{1 / 2}$ ). Yang et al. [8] demonstrated that the transverse rupture strength of Mo free $\mathrm{Ti}(\mathrm{C}, \mathrm{N}) \mathrm{WC} \mathrm{Cr}_{3} \mathrm{C}_{2}$ $\mathrm{C} \mathrm{Ni} \mathrm{xCr}$ cermets had a peak value of $\sim 2200 \mathrm{MPa}$ with an addition of $7.6 \mathrm{wt} \%$ of $\mathrm{Cr}$, and that the Vickers hardness was improved from $\sim 9$ to $\sim 11$ GPa with the $\mathrm{Cr}$ content. Acharya et al. [23] reported improved mechanical properties of $\mathrm{TiC} \mathrm{Ni}$ cermets by the addition of $10 \mathrm{wt} \%$ of $\mathrm{NiB}$, reaching hardness values of $27 \mathrm{GPa}$ and fracture toughness of $\sim 9 \mathrm{MPa} \mathrm{m}^{1 / 2}$. They ascribed such improvement to the fine and dense microstructure developed as a consequence of the low melting point of the boride phase. In a recent work, Chen et al. [16] studied the effect of the carbon addition on the microstructure and mechanical properties (hardness and TRS) of $\mathrm{Ti}(\mathrm{C}, \mathrm{N})$ based cermets. It was found that the addition of extra carbon powders can enhance the rearrangement of $\operatorname{Ti}(\mathrm{C}, \mathrm{N})$ particles during liquid phase sintering and thus increase their mechanical properties, which is associated with the higher relative densities. A summary of the mechanical properties (i.e. hardness, fracture toughness and bending strength) of the different cermets mentioned above with optimized secondary carbides addition is given in Table 1.

Other investigations have focused on the effect of the reduction of the $\operatorname{Ti}(\mathrm{C}, \mathrm{N})$ initial particle size on the microstructure and me chanical properties of $\mathrm{Ti}(\mathrm{C}, \mathrm{N}) \mathrm{WC}$ Ni cermets, where the small sizes were achieved either by using ultrafine powders or through mechanical milling. Jeon et al. [3] reported improved hardness as well as fracture toughness in the ultrafine system, as compared to conventional coarse $\mathrm{Ti}(\mathrm{C}, \mathrm{N})$ based cermets. Joardar et al. [4] studied the effect of nanocrystalline $\mathrm{Ni}$ binder on the mechanical properties of ultrafine $\mathrm{Ti}(\mathrm{C}, \mathrm{N})$ cermets. Cermets with nanocrystalline $\mathrm{Ni}$ showed a considerably improved microstructure over cermets with commercial coarse grade $\mathrm{Ni}$, exhibiting higher Vickers hardness values ( 16 GPa), along with a fracture toughness value of $\sim 9 \mathrm{MPa} \mathrm{m}^{1 / 2}$. Finally, Park et al. [5] prepared ultrafine cermets from
$(\mathrm{Ti}, \mathrm{W}) \mathrm{C}$ Ni and $(\mathrm{Ti}, \mathrm{W})(\mathrm{C}, \mathrm{N}) \mathrm{Ni}$ nanocrystalline powders obtained by carbo thermal reduction. Full density cermets obtained from these powders showed significantly improved fracture resistance, ranging between 11 and $14 \mathrm{MPa} \mathrm{m}^{1 / 2}$.

In addition to the above, the processing route may also have a significant influence on the mechanical properties of these mate rials. Although the most common route used for the preparation of cermets powders is still the traditional mechanical milling, cermets have been also processed through spark plasma sintering (SPS) [9], hot pressing (HP) $[10,12]$, self propagating high temperature syn thesis (SHS) [24-26], mechanical induced self sustaining reaction (MSR) $[9,10]$, hot isostatic pressing (HIP) or a combination of sin tering and HIP, under vacuum, nitrogen or argon atmosphere [27]. In 2015, Liu et al. [25] prepared dense $\mathrm{TiC}_{1-\mathrm{x}} \mathrm{N}_{\mathrm{x}} \mathrm{Ni}_{3} \mathrm{Ti}$ cermets directly by one step SHS. The as prepared cermets showed a ho mogeneous microstructure and a Vickers hardness of $\sim 12 \mathrm{GPa}$. Córdoba et al. [9] proposed a combination of MSR and SPS tech niques to obtain highly dense $\mathrm{Ti}_{\mathrm{x}} \mathrm{Ta}_{1-\mathrm{x}} \mathrm{C}_{0.5} \mathrm{~N}_{0.5}$ based cermets. Samples exhibiting smaller ceramic particles showed an optimal combination of microhardness and fracture toughness. In this re gard, Chicardi et al. [10] employed successfully the MSR for manufacturing cermets based on $\mathrm{Ti}$, Ti $\mathrm{Ta}$ and $\mathrm{Ti} \mathrm{Nb}$ carbonitrides using $\mathrm{Co}$ as binder phase and $\mathrm{Mo}_{2} \mathrm{C}$ as sintering additive obtaining smaller ceramic grains after sintered and reaching Vickers hardness values up to $15.8 \mathrm{GPa}$ with $\mathrm{K}_{\mathrm{IC}}$ of $3-4 \mathrm{MPa} \mathrm{m}^{1 / 2}$ and flexural strengths of 300-400 MPa. Table 2 shows a summary of the me chanical properties obtained in different cermets processed through various techniques. The data reveal a relatively wide range of reported hardness, fracture toughness and bending strength values depending on the material and processing route employed. This has been associated with the different microstructure of the materials. In fact, it is very challenging to get uniform and homo geneous microstructures, as well as to avoid the grain growth and hard phase cluster formation by the aforementioned techniques.

As an alternative to the above mentioned processing tech niques, colloidal processing has emerged as an attractive and affordable approach to be successfully implemented for the fabri cation of cermets [28-30].

This technique is a simple, low energy and costly efficient pro cedure that provides homogeneous composite materials, mini mizing processing defects, from high solid content aqueous suspensions of powders with fine particle size distribution (micrometric range). The success of this processing approach is based on two main interrelated factors. The first one is the control of the interparticle potentials in order to achieve high repulsion among particles, preventing the agglomeration and obtaining good dispersions [31]. The second factor is the rheology optimization of the suspensions, which depends on the level of repulsions of the particles in the media as well as on other variables such as solid content and processing additives [32,33].

Table 1

Mechanical properties of cermets with different secondary carbides of optimal amount addition.

\begin{tabular}{|c|c|c|c|c|c|c|}
\hline System & Secondary Carbide & $\begin{array}{l}\text { Optimal amount } \\
\text { [wt. \%] }\end{array}$ & $\begin{array}{l}\mathrm{HV} \\
{[\mathrm{GPa}]}\end{array}$ & $\begin{array}{l}\text { KIC } \\
{\left[\mathrm{MPa} \mathrm{m}^{1 / 2}\right]}\end{array}$ & $\begin{array}{l}\text { Bending strength } \\
\text { [MPa] }\end{array}$ & Ref. \\
\hline $\mathrm{Ti}(\mathrm{C}, \mathrm{N})-\mathrm{Ni}$ & WC & 25 & 14.2 & 8.8 & & [3] \\
\hline $\mathrm{Ti}(\mathrm{C}, \mathrm{N})-\mathrm{NiCo}$ & & 15 & 17.5 & & 1500 & [18] \\
\hline $\mathrm{Ti}(\mathrm{C}, \mathrm{N})-\mathrm{Fe}$ & $\mathrm{Mo}_{2} \mathrm{C}$ & 15 & 14.7 & & 1560 & [17] \\
\hline $\mathrm{Ti}(\mathrm{C}, \mathrm{N})-\mathrm{NiCo}$ & & 10 & 17.7 & & 1300 & [18] \\
\hline $\mathrm{Ti}(\mathrm{C}, \mathrm{N})-\mathrm{Ni}$ & $\mathrm{Ta}$ & 38 & 17.8 & 6.9 & & [7] \\
\hline $\mathrm{Ti}(\mathrm{C}, \mathrm{N})-\mathrm{NiCo}$ & $\mathrm{TaC}$ & 7.0 & 16.9 & & 1580 & [18] \\
\hline $\mathrm{Ti}(\mathrm{C}, \mathrm{N})-\mathrm{Ni}$ & $\mathrm{Cr}$ & 7.6 & 10.5 & & & [8] \\
\hline TiC-Ni & $\mathrm{NiB}$ & 10 & 27.1 & 9.0 & & [23] \\
\hline $\mathrm{Ti}(\mathrm{C}, \mathrm{N})-\mathrm{Fe}$ & $\mathrm{C}$ & 1.0 & 9.9 & & 2480 & [16] \\
\hline
\end{tabular}

${ }^{a}$ Bending strength may have been measured by different methods; the mean value is reported for comparative purposes. 
Table 2

Properties of cermets via different processes.

\begin{tabular}{|c|c|c|c|c|c|c|}
\hline Processing & System & $\begin{array}{l}\operatorname{Ti}(C, N) \text { Size } \\
{[\mu \mathrm{m}]}\end{array}$ & $\begin{array}{l}\mathrm{HV} \\
{[\mathrm{GPa}]}\end{array}$ & $\mathrm{K}_{\mathrm{IC}}\left[\mathrm{MPa} \mathrm{m}^{1 / 2}\right]$ & $\begin{array}{l}\text { Bending strength } \\
\text { [MPa] }\end{array}$ & Ref. \\
\hline PM Route & $\mathrm{Ti}(\mathrm{C}, \mathrm{N})-\mathrm{WC}-\mathrm{Ni}$ & $\begin{array}{l}\mathrm{UF}<1 \\
35\end{array}$ & $\begin{array}{l}{\left[\begin{array}{ll}13.6 & 14.5\end{array}\right]} \\
{\left[\begin{array}{ll}7 & 7.5\end{array}\right]}\end{array}$ & {$\left[\begin{array}{ll}7.3 & 8.8\end{array}\right]$} & & [3] \\
\hline PM Route & $\begin{array}{l}\mathrm{Ti}(\mathrm{C}, \mathrm{N})-\mathrm{WC}-\text { nano } \mathrm{Ni} \\
\mathrm{Ti}(\mathrm{C}, \mathrm{N})-\mathrm{WC}-\mathrm{Ni}\end{array}$ & 0.7 & $\left.\begin{array}{ll}{[12.5} & 16.1\end{array}\right]$ & $\left.\begin{array}{ll}{[8.4} & 9.1] \\
{[7.3} & 8.8\end{array}\right]$ & & [4] \\
\hline PM Route & $(\mathrm{Ti}, \mathrm{W})(\mathrm{C}, \mathrm{N})-\mathrm{Ni}$ & $\begin{array}{l}\text { UF } \sim 0.4 \\
34\end{array}$ & $\begin{array}{l}{\left[\begin{array}{ll}11.2 & 12.2\end{array}\right]} \\
{\left[\begin{array}{ll}8.8 & 9.0\end{array}\right]}\end{array}$ & $\begin{array}{l}{\left[\begin{array}{ll}12.0 & 12.6\end{array}\right]} \\
{\left[\begin{array}{ll}7.0 & 7.2\end{array}\right]}\end{array}$ & & {$[5]$} \\
\hline PM Route & $\mathrm{Ti}(\mathrm{C}, \mathrm{N})-\mathrm{Fe}$ & 7.5 & {$\left[\begin{array}{ll}5.6 & 7.0\end{array}\right]$} & & & [15] \\
\hline PM Route & $\mathrm{Ti}(\mathrm{C}, \mathrm{N})-\mathrm{Mo}_{2} \mathrm{C}-\mathrm{Ni}$ & 2.33 .6 & {$\left[\begin{array}{ll}12.1 & 14.9\end{array}\right]$} & {$\left[\begin{array}{ll}10.3 & 14.2\end{array}\right]$} & & [6] \\
\hline SPS & $(\mathrm{Ti}, \mathrm{Ta})(\mathrm{C}, \mathrm{N})-\mathrm{Co}$ & & {$\left[\begin{array}{ll}14.0 & 17.4\end{array}\right]$} & {$\left[\begin{array}{ll}3.2 & 5.6\end{array}\right]$} & & [9] \\
\hline PM Route & $\mathrm{Ti}(\mathrm{C}, \mathrm{N})-\mathrm{WC}-\mathrm{Mo}_{2} \mathrm{C}-\mathrm{NiCo}$ & 0.5 & $\sim 11.1$ & $\sim 9.4$ & $\sim 1850$ & [11] \\
\hline $\mathrm{HP}$ & $\begin{array}{l}\text { A. } \mathrm{Ti}(\mathrm{C}, \mathrm{N})-\left(\mathrm{WC}-\mathrm{Mo}_{2} \mathrm{C}\right)-\mathrm{NiCo} \\
\text { B. } \mathrm{Ti}(\mathrm{C}, \mathrm{N})-(\mathrm{WC}-\mathrm{TiC})-\mathrm{NiCoMo}\end{array}$ & 0.5 & $\begin{array}{l}\sim 17.1 \\
\sim 13.7\end{array}$ & $\begin{array}{l}\sim 6.0 \\
\sim 9.0\end{array}$ & $\begin{array}{l}\sim 1125 \\
\sim 1125\end{array}$ & [12] \\
\hline PM Route & & & $\begin{array}{l}\sim 11.8 \\
\sim 11.8\end{array}$ & $\begin{array}{l}\sim 11.0 \\
\sim 11.0\end{array}$ & $\begin{array}{l}\sim 1375 \\
\sim 1250\end{array}$ & \\
\hline $\mathrm{HP}$ & $(\mathrm{Ti}, \mathrm{Mt})(\mathrm{C}, \mathrm{N})-\mathrm{Mo}_{2} \mathrm{C}-\mathrm{Co} \mathrm{Mt} \mathrm{Ta}, \mathrm{Nb}$ & & {$\left[\begin{array}{ll}9.6 & 15.8\end{array}\right]$} & {$\left[\begin{array}{ll}3.1 & 4.6\end{array}\right]$} & {$\left[\begin{array}{ll}230 & 485\end{array}\right]$} & {$[10]$} \\
\hline PM Route & $\mathrm{Ti}(\mathrm{C}, \mathrm{N})-\mathrm{Mo}_{2} \mathrm{C}-\mathrm{Cr}_{3} \mathrm{C}_{2}-\mathrm{Fe}$ & 5.13 & {$\left[\begin{array}{ll}3.1 & 7.7\end{array}\right]$} & & {$\left[\begin{array}{ll}1000 & 2055\end{array}\right]$} & [16] \\
\hline
\end{tabular}

PM Route: Uniaxial pressing + Pressureless Sintering (PLS).

UF: Ultrafine.

In previous works, colloidal and powder metallurgy techniques were successfully combined to obtain cermet bulk samples with compositions in the system $\mathrm{Ti}(\mathrm{C}, \mathrm{N}) \mathrm{FeNi}$ [30]. Preliminary hardness measurements revealed a correlation between microstructure and hardness with the processing route, which was associated with the amount of porosity and metallic binder (FeNi). In the present paper, the effect of the processing route, as well as the effect of the metal binder and carbon content on the strength and fracture toughness has been investigated. Biaxial strength was measured in all samples using the ball on three balls (B3B) method on disc shaped speci mens. Single Edge V Notched Beam (SEVNB) specimens were tested under four point bending (4 PB) in order to determine the fracture resistance. Microstructural and fractographic analyses were performed on selected specimens to interpret the experi mental results.

\section{Experimental}

\subsection{Materials and characterization of samples}

Powders used in this study were titanium carbonitride (Ti(C,N), $\mathrm{Ti}\left(\mathrm{C}_{0.5}, \mathrm{~N}_{0.5}\right)$ Grade $\left.\mathrm{C}\right)$ and iron (Fe, Fe $\left.\mathrm{SM}\right)$ both provided by H.C. Starck (Germany) and nickel (Ni, Ni 210H) supplied by INCO (Can ada). Particle size and density of the as received powders were determined with a laser analyzer (Mastersizer S, Malvern in struments Ltd. UK) and with a Monosorb Multipycnometer (Quantachrome Corporation, USA), respectively. Results are shown in Table 3.

From these commercial powders, $\mathrm{Ti}(\mathrm{C}, \mathrm{N})$ and $\mathrm{Fe} / \mathrm{Ni}$ high solid content suspensions were formulated using water as dispersion media, as described elsewhere [30]. After milling by a simple volumetric mixing, both stable suspensions were mixed to fit the desired final composition of the ceramic/metal composites $(85 / 15$ and $80 / 20 \mathrm{vol} \%)$. The metallic binder phase was designed with a fixed $\mathrm{Fe} / \mathrm{Ni}$ composition of $85 / 15$ wt \%. In order to evaluate the

Table 3

Characterization of the as-received powder.

\begin{tabular}{llll}
\hline Characteristics & Powder & & \\
\cline { 2 - 4 } & $\mathrm{Ti}(\mathrm{C}, \mathrm{N})$ & $\mathrm{Fe}$ & $\mathrm{Ni}$ \\
\hline $\mathrm{D}_{\mathrm{v} 50}(\mu \mathrm{m})$ & 2.1 & 3.5 & 1.7 \\
Density $\left(\mathrm{g} / \mathrm{cm}^{3}\right)$ & 5.1 & 7.8 & 8.9 \\
\hline
\end{tabular}

Table 4

Formulation of sintered specimens.

\begin{tabular}{llll}
\hline Sample & $\begin{array}{l}\text { Ceramic } \\
\text { reinforcement } \\
\text { Ti(C,N) vol\% }\end{array}$ & $\begin{array}{l}\text { Metal matrix } \\
\text { reinforcement } \\
\text { Fe/Ni vol\% }\end{array}$ & $\begin{array}{l}\text { Carbon } \\
\text { addition }^{\mathrm{a}} \\
\text { wt.\% }\end{array}$ \\
\hline SC 15FeNiC & 85 & $15(85 / 15 \mathrm{wt} \%)$ & +0.5 \\
SC-CIP 15FeNi & 85 & $15(85 / 15 \mathrm{wt} \%)$ & +0.5 \\
SC-CIP 15FeNiC & 85 & $15(85 / 15 \mathrm{wt} \%)$ & +0.5 \\
SDP 15FeNi & 85 & $15(85 / 15 \mathrm{wt} \%)$ & \\
SDP 15FeNiC & 85 & $15(85 / 15 \mathrm{wt} \%)$ & +0.5 \\
SDP 20FeNi & 80 & $20(85 / 15 \mathrm{wt} \%)$ & +0 \\
SDP 20FeNiC & 80 & $20(85 / 15 \mathrm{wt} \%)$ & +0.5 \\
\hline
\end{tabular}

a Carbon addition with respect to the weight of matrix.

effect of a small addition of carbon, a graphite suspension $(10 \mathrm{~g} / \mathrm{L}$ in ethanol) using Black Carbon (ISTAM, Germany) was added to fit the different compositions labeled in Table 4.

These suspensions were processed to obtain samples through a combination of colloidal and powder metallurgical techniques. The three processing routes selected were: (a) Slip Casting (SC), (b) Slip Casting followed by Cold Isostatic Pressing (SC CIP) to evaluate the effect of increasing the green density on the final mechanical properties of the sintered materials, and (c) Spray Dry and Uniaxial Pressing (SDP) where high solid content suspensions were sprayed dried in order to obtain spherical granules able to be shaped by uniaxial pressing using a Labplant SD 05 (North Yorkshire, UK).

Subsequently, all green compacts, listed in Table 4, were sintered in vacuum $\left(10^{-5} \mathrm{mbar}\right)$ at $1450{ }^{\circ} \mathrm{C}$ for $120 \mathrm{~min}$. All thermal treat ments included a dwell of $30 \mathrm{~min}$ at $800{ }^{\circ} \mathrm{C}$. Density and porosity measurements of sintered samples can be found in previous work [34].

Carbide contiguity and binder mean free path were deduced from best fit equations, attained after compilation and analysis of data published in the literature (e.g. Refs. $[35,36]$ ), on the basis of empirical relationships given by Roebuck and Almond [35] but extending them to include carbide size influence [37,38].

\subsection{Evaluation of biaxial strength}

The biaxial strength was measured on disc shaped samples using the ball on three balls (B3B) method [39-41], where the specimen is supported on three balls and loaded symmetrically by a fourth ball (Fig. 1a). In this loading situation, the three point 

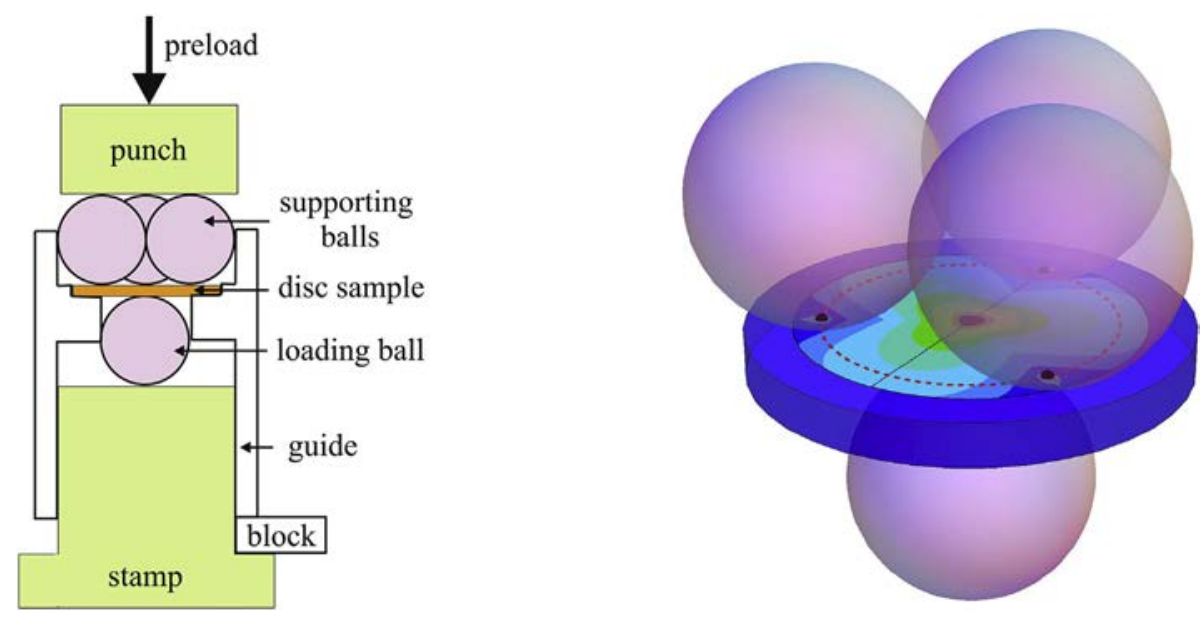

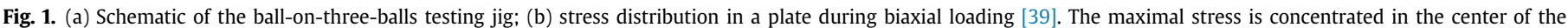
specimen surface.

support guarantees well defined three point contacts (see Fig. 1b), thus enabling even the testing of specimens with non paralle surfaces (e.g. as sintered specimens). This test has been recog nized to be very tolerant for some out of flatness of the disc and also for other small geometries or some misalignment [40], and has been also successfully used in hardmetals (see for instance [42]). The main advantages of the B3B testing method are the high ac curacy, easy testing in different environments and avoidance of edge effects (e.g. fracture of bending bars from the edges). Furthermore, friction is much smaller than in the commonly used bending tests. For these reasons, the B3B test can also be used in as sintered and small specimens [43]. Compared to standard 4 PB or $3 \mathrm{~PB}$, the $\mathrm{B} 3 \mathrm{~B}$ requires less material to be tested, and the fracture is located away from the applied load and well localized (i.e. easy to identify the failure origin). It is very useful for comparing for instance the strength of materials with slightly differences in compositions (e.g. the ones used in our work), and avoid that measurement uncertainties associated with the testing procedure might mask the results (see Ref. [44] for more details). In the B3B method a small surface (and volume) of the specimen (i.e the midpoint of the disc surface, opposite to the loading ball) is set under a well defined biaxial stress field during the test. The cor responding area under tensile stress contributes to the so called "effective surface"; the same applies for the volume, referred to as "effective volume". Fig. 1b shows a view of the B3B jig with the specimen between the four balls. In our case all four balls had a diameter of $9.524 \mathrm{~mm}$ and $6.350 \mathrm{~mm}$ depending of the diameter of the samples, giving a support diameter of $10.997 \mathrm{~mm}$ and $7.332 \mathrm{~mm}$, respectively [39]. The tensile loaded surfaces of the B3B specimens (disks of $\sim 1.20 \mathrm{~mm}$ in thickness and $13.75 \mathrm{~mm}$ in diameter for the SDP and $\sim 1.20 \mathrm{~mm}$ in thickness and $9.00 \mathrm{~mm}$ in diameter for the SC and SC CIP) were carefully ground and polished in diamond to 1 microns finish on one side to reach the same surface quality. Nevertheless, one limitation of the method is associated with the small tested area (or volume). The corre sponding stress distribution in the disc during biaxial loading is shown in Fig. 1b. The maximal stress is located in the center of the three balls. It can be inferred that only the central region, i.e. approx. $1 / 20$ of the support radius, is stressed by more than $90 \%$ of the maximal stress. As a consequence, some potential critical de fects (lying off the stressed region) might not be activated during the test.

All tests were performed in a universal testing machine (Zwick Z010, Zwick/Roell, Ulm, Germany). A pre load of $10 \mathrm{~N}$ was applied in all cases. The tests were conducted under cross head displace ment control at a rate of $1 \mathrm{~mm} / \mathrm{min}$ (environmental conditions of $23{ }^{\circ} \mathrm{C}$ and relative humidity of $34 \%$ ). The load was increased until fracture, and the fracture load, $F$, was used to calculate the maximum tensile biaxial stress in the specimen. In order to ensure statistical significance in the Weibull analyses, between 13 and 28 specimens were tested for each sample. All results were interpreted in the framework of Weibull theory according to the EN 8435 standard [43] under the assumption that the materials exhibit a brittle behavior. The failure stress was calculated after testing from the maximum tensile stress $\sigma_{\max }$, given by:

$\sigma_{\max } f \cdot \frac{F}{t^{2}}$

where $t$ is the specimen thickness and $f$ is a dimensionless factor depending on geometrical conditions of the testing setup and the specimen's Poisson's ratio, calculated using finite element analysis [45]. For instance, considering averaged dimensions of $13.75 \mathrm{~mm}$ and $9.00 \mathrm{~mm}$ diameter, with a thickness of $1.20 \mathrm{~mm}$ (taken Pois son's ratio as $\sim 0.2$ ), the calculated factor resulted in $f \sim 1.9$ and $f \sim 1.7$, respectively.

\subsection{Evaluation of fracture toughness}

The fracture toughness $\left(\mathrm{K}_{\mathrm{Ic}}\right)$ of the different SDP composites was determined using the Single Edge V Notch Beam method (SEVNB) on standard specimens (7 specimens from each class) of di mensions $3 \times 4 \times 27 \mathrm{~mm}^{3}$. A razor blade automatic machine was utilized to create the notch, which was sharpened to a radius of less than $5 \mu \mathrm{m}$ in order to minimize the influence of notch radius on $\mathrm{K}_{\mathrm{Ic}}$ values [46]. Typical notch corresponding to one of the four different SDP samples can be seen in Fig. 2. It can be appreciated that the notch radius is below the size of the microstructural unit of the cermet.

The notched specimens were then fractured in four point bending tests under a cross head displacement rate of $0.1 \mathrm{~mm} /$ min (environmental conditions of $22.5{ }^{\circ} \mathrm{C}$ and $25 \% \mathrm{RH}$ ) on a uni versal testing machine (Zwick Z010, Zwick/Roell, Ulm, Germany) according to EN 8431 [47].

\subsection{Fractographic analyses}

In order to identify the fracture origin in the B3B samples, 


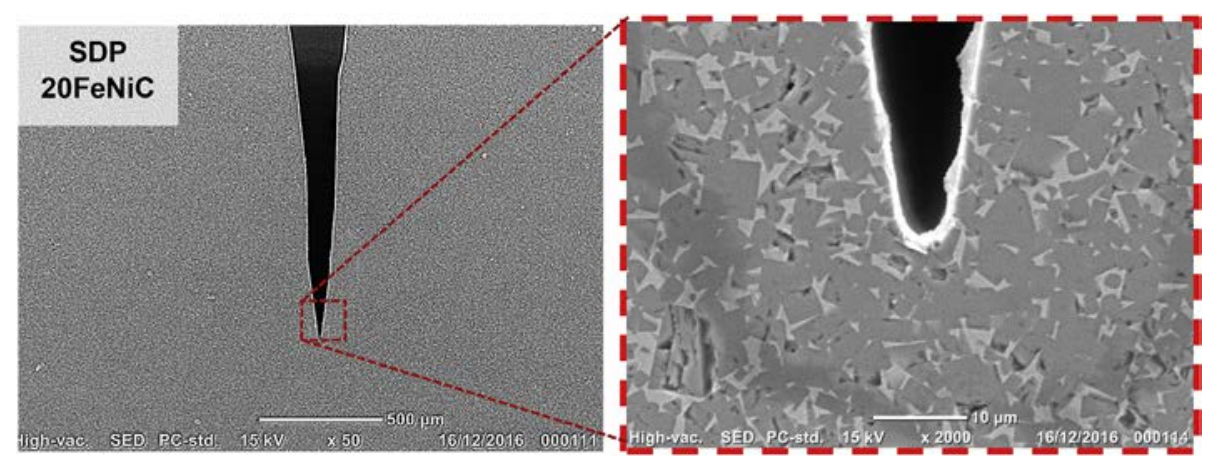

Fig. 2. Typical notch tip of the SEVNB samples fabricated by the SDP process. The size of the notch tip radius is below $5 \mu$ m, in the order of the Ti(C,N) grain size.

selected broken specimens were analyzed with both an optical stereo microscope (Olympus SZH10, Olympus Ltd., Tokyo, Japan) and a Scanning Electron Microscope (Jeol JCM 6000Plus Neo scope $^{\mathrm{TM}}$, Jeol Ltd., Tokyo, Japan). Furthermore, the fracture surface of selected SEVNB SDP samples used for toughness measurements were also analyzed with the SEM, aiming to identify differences in the fracture mechanisms related to different carbon addition and matrix volume content.

\section{Results and discussion}

\subsection{Strength distribution}

Fig. 3 shows the results of the B3B tests conducted in the different cermets. The biaxial strength distribution for every sam ple is represented in a Weibull diagram, where the probability of failure, $P_{\mathrm{f}}$, is plotted versus the failure stress, $\sigma_{\mathrm{f}}$ (calculated for every specimen according to Eq. (1)). The Weibull parameters $\sigma_{0}$ (char acteristic strength) and $m$ (Weibull modulus) of each sample were calculated according to EN 8435 standard [43]. The full lines represent the best fit to the strength data using the maximum likelihood method and the $90 \%$ confidence intervals. The Weibull parameters ( $\sigma_{0}$ and $m$ ) and their corresponding 90\% confidence intervals are listed in Table 5.

The tensile strength is associated with the presence of flaws, which are distributed within the specimens or in their surface. The strength of a specimen is determined by the most critical defect (which is, in general, the largest one in the most highly stressed location). Therefore the strength has to be described by a distri bution function, which reflects the size distribution of flaws in the specimens. In Fig. 3 it can be observed that all cermet samples follow a Weibull distribution, indicating an underlying flaw size frequency function in all cermets of the type $g \propto a^{-p}$, with $m$ 2(l $p 1)$ (see Ref. [43] for more details). The scatter of strength in
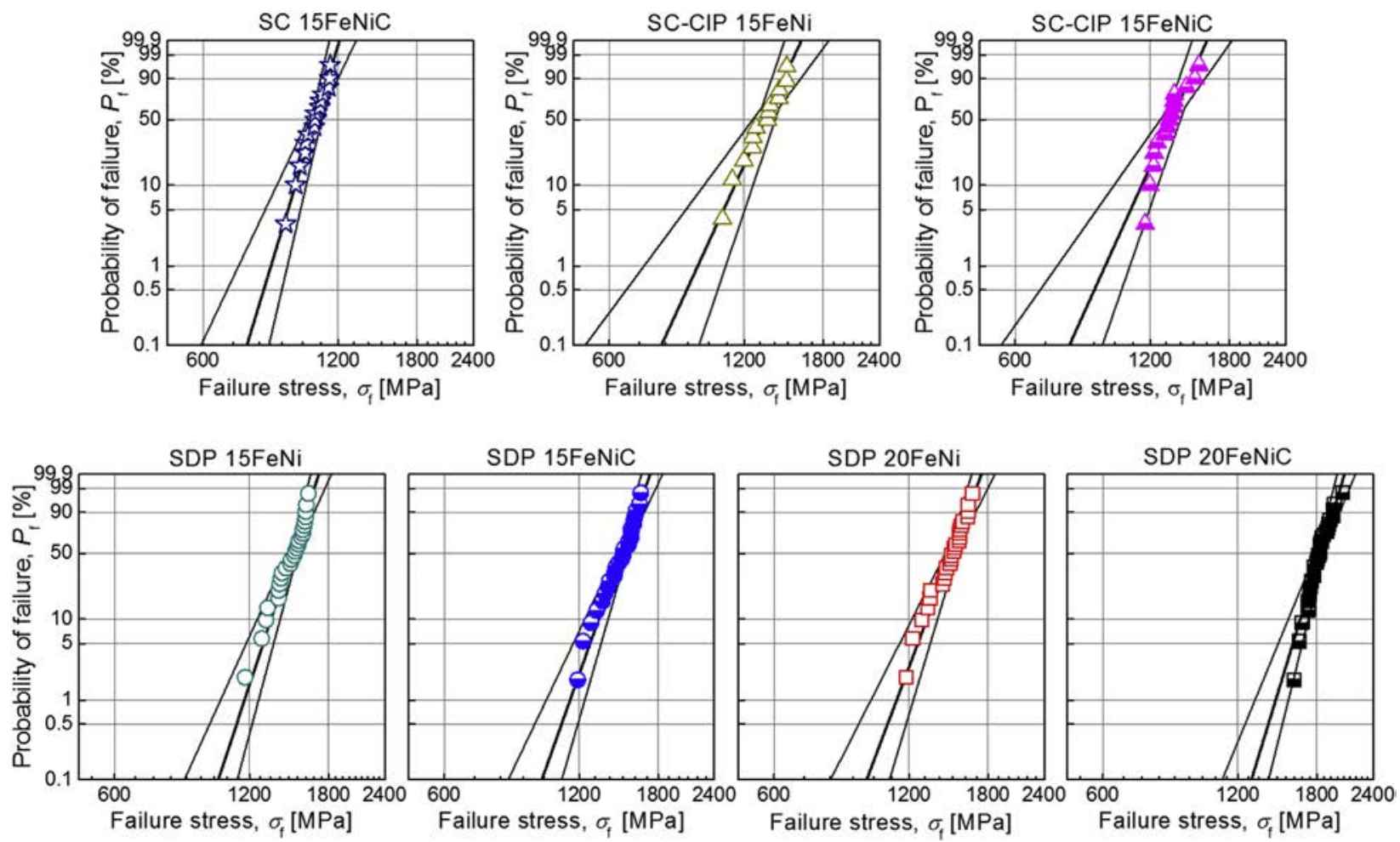

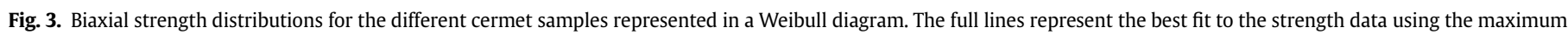
likelihood method, together with the $90 \%$ confidence intervals. 
Table 5

Characteristic strength, $\sigma_{0}$, and Weibull modulus, $m$, for the different cermet samples, along with the $90 \%$ confidence intervals. The porosity determined for the specimens (in vol. \%) is also given for comparison, as taken from Ref. [34].

\begin{tabular}{|c|c|c|c|c|}
\hline Sample & $\begin{array}{l}\text { Charac } \\
\sigma_{0}[\mathrm{MP}\end{array}$ & $\begin{array}{l}\text { t. Strength } \\
\text { a] }\end{array}$ & $\begin{array}{l}\text { Porosity } \\
(\%)\end{array}$ & $\begin{array}{l}\text { Weibull modulus } \\
m[-]\end{array}$ \\
\hline SC $15 \mathrm{FeNiC}$ & $\begin{array}{l}1088 \\
{[1059}\end{array}$ & 1118] & 7.80 & $\begin{array}{l}19 \\
{\left[\begin{array}{ll}12 & 24\end{array}\right]}\end{array}$ \\
\hline SC-CIP 15FeNi & $\begin{array}{l}1374 \\
{[1314}\end{array}$ & 1437] & 2.75 & $\left.\begin{array}{ll}12 & \\
8 & 17\end{array}\right]$ \\
\hline SC-CIP $15 \mathrm{FeNiC}$ & $\begin{array}{l}1375 \\
{[1321}\end{array}$ & 1432] & 3.66 & $\left.\begin{array}{ll}13 & \\
{[8} & 16\end{array}\right]$ \\
\hline SDP $15 \mathrm{FeNi}$ & $\begin{array}{l}1529 \\
{[1497}\end{array}$ & 1562] & 1.15 & $\begin{array}{l}17 \\
{\left[\begin{array}{ll}12 & 21\end{array}\right]}\end{array}$ \\
\hline SDP 15FeNiC & $\begin{array}{l}1528 \\
{[1495}\end{array}$ & 1562] & 1.81 & $\begin{array}{l}16 \\
{\left[\begin{array}{ll}12 & 20\end{array}\right]}\end{array}$ \\
\hline SDP 20FeNi & $\begin{array}{l}1529 \\
{[1493}\end{array}$ & 1566] & 0.44 & $\begin{array}{l}15 \\
{[11} \\
{[19]}\end{array}$ \\
\hline SDP 20FeNiC & $\begin{array}{l}1867 \\
{[1832}\end{array}$ & 1903] & 0.99 & $\begin{array}{l}19 \\
{\left[\begin{array}{ll}14 & 23\end{array}\right]}\end{array}$ \\
\hline
\end{tabular}

each sample can be related to the different size of the critical flaw causing the failure. Fig. 4 represents the characteristic strength versus the Weibull modulus for all cermets tested.

Fig. 5 shows the characteristic biaxial strength versus the porosity (in \%) for all materials tested to analyze the correlation between these two parameters. The main observation is that the lower the porosity, the higher the strength, as it was expected. As a consequence, the materials processed by SDP show the highest values of strength. It is worth pointing out the significant difference in strength between 20FeNiC and 20FeNi (with and without C addition, respectively). Nevertheless, such a difference cannot be observed between $15 \mathrm{FeNiC}$ and $15 \mathrm{FeNi}$ cermets.

Fig. 6a shows a Weibull diagram comparing the strength dis tribution of $15 \mathrm{FeNiC}$ samples fabricated by different processing routes, i.e. SC, SC CIP and SDP. For a given composition, for example $15 \mathrm{FeNiC}$, bulk pieces processed by SC showed a relatively lower sintered density (92.20\%) and lower strength values ( 1090 MPa) than samples obtained by the other processing methods, SC CIP $(96.34 \%, \sim 1380 \mathrm{MPa})$ and $\operatorname{SDP}(98.19 \%, \sim 1530 \mathrm{MPa})$. The same trend was observed for the $15 \mathrm{FeNi}$ specimens.

Fig. 6b shows a Weibull diagram of the strength distribution of the two 20FeNi samples, with and without carbon addition. It is interesting pointing out that only in the case of 20FeNi samples a clear difference can be appreciated in the strength, the carbon addition improving the mechanical behavior. For the case of $15 \mathrm{FeNi}$,

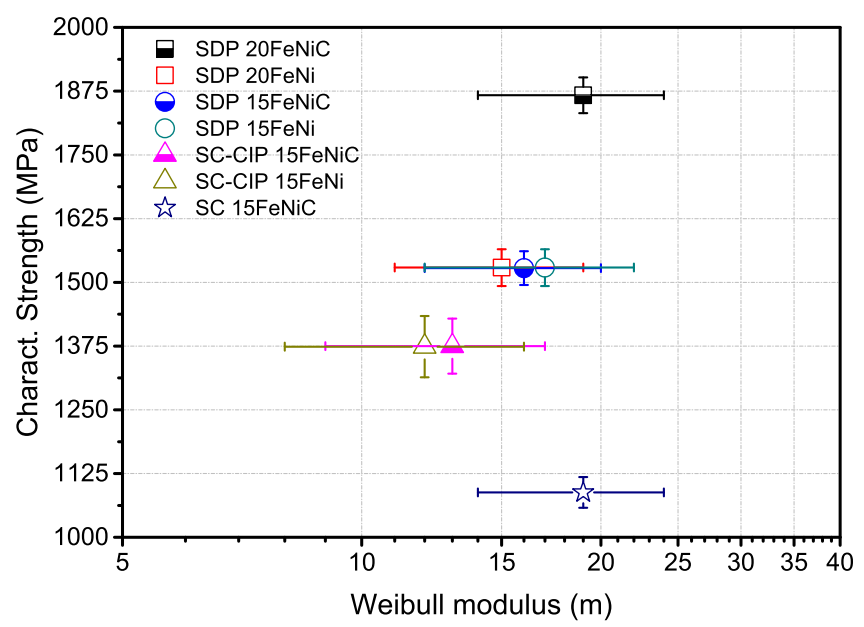

Fig. 4. Biaxial characteristic strength versus Weibull modulus.

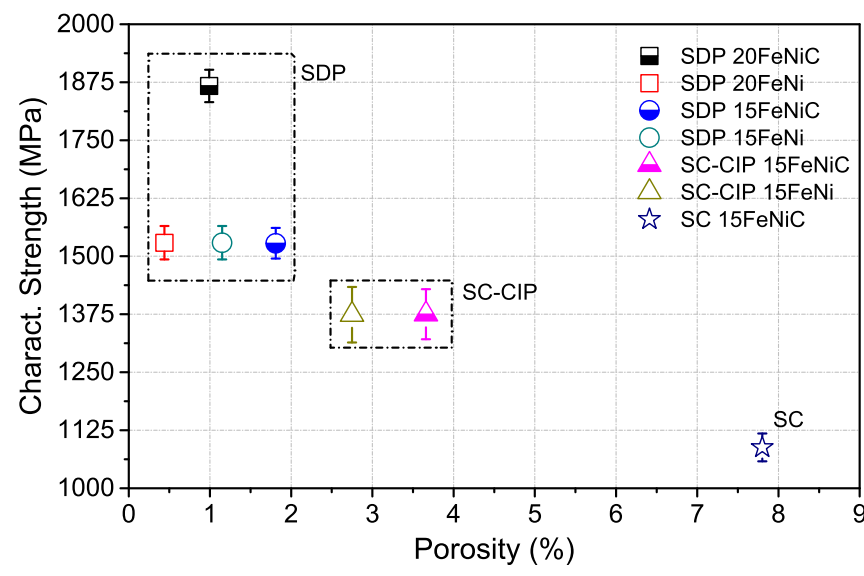

Fig. 5. Biaxial characteristic strength versus porosity for SC, SC-CIP and SDP cermets.

no difference could be observed (see Table 5).

As it can be seen in the reported bibliography, the values of transverse rupture strength of sintered $\mathrm{Ti}(\mathrm{C}, \mathrm{N})$ cermets depends strongly of the binder phase used and its volume faction, the addition of secondary phases as well as the carbon addition. However, the measured $\sigma_{0}$ and $m$ values are comparable to the formulation reported in the literature for the $\mathrm{Ti}(\mathrm{C}, \mathrm{N})$ based cermets, or a similar composition, processed by other techniques and/or using other binders [10-12,16-18].

In order to identify the size, location and type of critical flaw, a fractographic analysis was performed in selected specimens cor responding to each cermet composition.

\subsection{Failure analyses on $B 3 B$ samples}

Fig. 7a shows a typical broken specimen after B3B biaxial bending. The fracture origin is located in the center of the disc. Typical volume flaws, which may act as fracture origins, are pores, impurity inclusions, lakes of binder, agglomerates, etc. In order to identify the type of critical defect, a fractographic analysis was performed in selected samples. Fig. $7 \mathrm{~b}$ to $\mathrm{h}$ shows representative critical flaws corresponding to the different cermet samples tested under B3B. The top side in the figures correspond to the tensile side. An inset of the broken sample is also given to illustrate the macroscopic fracture. The broken lines indicate the fracture direction.

In most of the samples investigated in this work, the fracture origin resulted to be a large pore in the surface and/or subsurface of our materials, which can be modelled by a spherical cavity with a diameter of about $25 \mu \mathrm{m}$. Macroscopic brittle fracture was controlled by the extension of small flaws that were dispersed in the material and which behave like cracks. As it was explained in the previous section, there is a strong correlation between the processing route and the appearance of critical flaws (see Fig. 5). As a consequence of that, the biaxial strength of the $\mathrm{Ti}(\mathrm{C}, \mathrm{N}) \mathrm{FeNi}$ composites fabricated through the SDP process showed a rela tively high characteristic strength value compared to the charac teristic strength of the SC CIP and SC. However, the effect of carbon was not so evident in the fractography.

\subsection{Fracture resistance and failure analyses on SDP samples using SEVNB method}

The fracture toughness was evaluated following the VAMAS procedure on pre notched specimens [48]: 
a)

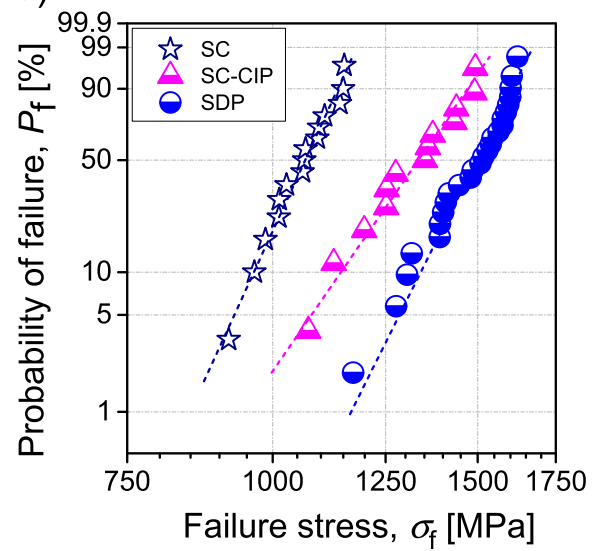

b)

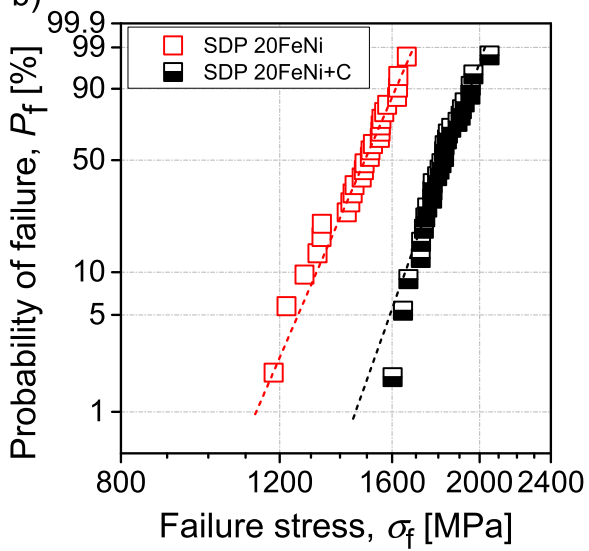

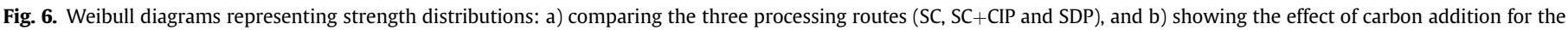
SDP 20FeNi samples.

$K_{I C} \quad Y^{\prime} \cdot \sigma \cdot \sqrt{ } a \quad \frac{F}{B \sqrt{ } W} \cdot \frac{S_{O} \quad S_{i}}{W} \cdot \frac{3 \sqrt{ } \delta}{2(1 \quad \delta)^{1.5}} \cdot Y$

where $\sigma$ is the failure stress, $F$ the fracture load (in N), $S_{0}$ and $S_{\mathrm{i}}$ are the outer and inner spans respectively (in $\mathrm{m}$ ), $B$ and $W$ are the specimen width and thickness respectively (in $\mathrm{m}$ ) and $Y$ is a geo metric factor defined for an edge crack of length $a$, defined as:

$Y \quad 1.9887 \quad 1.326 \cdot \delta \frac{\left(\begin{array}{ll}3.49 & 0.68 \cdot \delta+1.35 \cdot \delta^{2}\end{array}\right) \cdot \delta \cdot\left(\begin{array}{ll}1 & \delta\end{array}\right)}{\left(\begin{array}{ll}1 & \delta\end{array}\right)^{2}}$

with:

$$
\delta \quad \frac{a}{W}
$$

Additionally, to account for the contribution of the metallic matrix to the fracture energy of the cermets, the work of fracture $(\gamma$ WOF $)$ was determined from the area under the stable load displacement curves divided by twice the area of the un notched part of the cross section of the samples, ${ }^{1}$ according to [49]. As it can be seen in Table 6 , there is a positive correlation between $\gamma$ woF, $\mathrm{K}_{\mathrm{Ic}}$ and the FeNi content. The FeNi content was evaluated in terms of mean free path and contiguity.

Fig. 8 shows the load vs. cross head displacement curves cor responding to the four SDP specimens. All specimens show a typical brittle behavior (i.e. crack propagates unstable when the applied stress intensity factor overcomes the fracture toughness of the material). It should be noticed that in this plot the slope of the $15 \mathrm{FeNi}$ specimens is similar to that of the 20FeNi samples, but with a lower fracture load (for both samples with or without carbon addition) as it can be seen in the work of fracture (Table 6). This behavior indicates that the higher fracture toughness value in 20FeNi samples $\left(\sim 14 \mathrm{MPa} \mathrm{m}{ }^{1 / 2}\right)$ must be related to higher metal content. In fact, as it can be inferred from the microstructures, for such composites, the $\mathrm{Ti}(\mathrm{C}, \mathrm{N})$ is better surrounded by FeNi metal phase. The carbon addition did not significantly affect the measured fracture toughness of the materials. However, the

\footnotetext{
${ }^{1}$ It is assumed that all the work done was consumed in the growth of the crack and no significant elastic energy was stored in the specimen during testing.
}

strength results revealed a significant improvement in the 20FeNi specimens formulated with carbon. Table 6 also shows the ceramic contiguity and the binder mean free path, which were calculated to compare the proposed formulations and rationalize the effects of their microstructures on its mechanical behavior. The two param eters exhibited an opposite trend, i.e, the contiguity increased and the mean free path decreased with increasing the volume fraction of ceramic phase. In this case $\mathrm{K}_{\mathrm{Ic}}$ measurements were found to be directly and inversely proportional to the binder mean free path and ceramic contiguity respectively [50].

The macroscopic effect of the metal phase on the crack propa gation can be seen in Fig. 9. A very slightly difference can be recognized between the two binder compositions in terms of crack path. Whereas fractured $15 \mathrm{FeNiC}$ specimens show straight crack propagation, a slightly more tortuous crack path can be identified in the $20 \mathrm{FeNiC}$ ones. As expected, the $\gamma_{\text {woF }}$ measured for the $20 \mathrm{FeNiC}$ cermets is relatively higher than the $15 \mathrm{FeNiC}$ ones. Very interesting is the difference between composites formulated with carbon. Whereas the $15 \mathrm{FeNiC}$ shows the lower value of $\gamma_{\mathrm{WOF}}\left(\sim 1300 \mathrm{~J} / \mathrm{m}^{2}\right)$, the $20 \mathrm{FeNiC}$ reveals a relatively high level of $\gamma_{\mathrm{WOF}}\left(\sim 1500 \mathrm{~J} / \mathrm{m}^{2}\right)$.

This may be explained by observing the fracture surfaces of the SEVNB specimens. Fig. 10 shows microfracture features from the four SDP specimens. All cermets exhibit brittle fracture behavior on the macroscale, but on the microscale both the brittle fracture of the ceramic phase and the ductile fracture of the binder phase can be distinguished. This brittle fracture of the ceramic phase follows the transgranular mode of fracture characterized by the typical "river like" pattern. This pattern occurs when the crack direction deviates from the crystallographic lattice plane of the $\mathrm{Ti}(\mathrm{C}, \mathrm{N})$ phase. The cleavage fracture path through the carbide can either follow the crystallographic plane with relatively smooth surface that in creases the deviation from the crack direction or return closer to the crack direction by jumping between the crystallographic planes, yielding the river like ripples or steps on the surface. On the other hand, the fracture along the carbide binder interface has remnants of the plastically fractured binder phase with shallow dimples on the smooth surface of the carbide. It is also important to notice the low amount of close porosity found in all cases, which is indicative of the proper sintering process.

It is worth mentioning that not all fractures were identical, revealing differences among the different compositions. It is clear how a greater concentration of dimples appears as the metal con tent increases in the composition of the cermet (from $15 \mathrm{vol} \%$ to $20 \mathrm{vol} \%$ ). This phenomenon suggests that the material had broken 

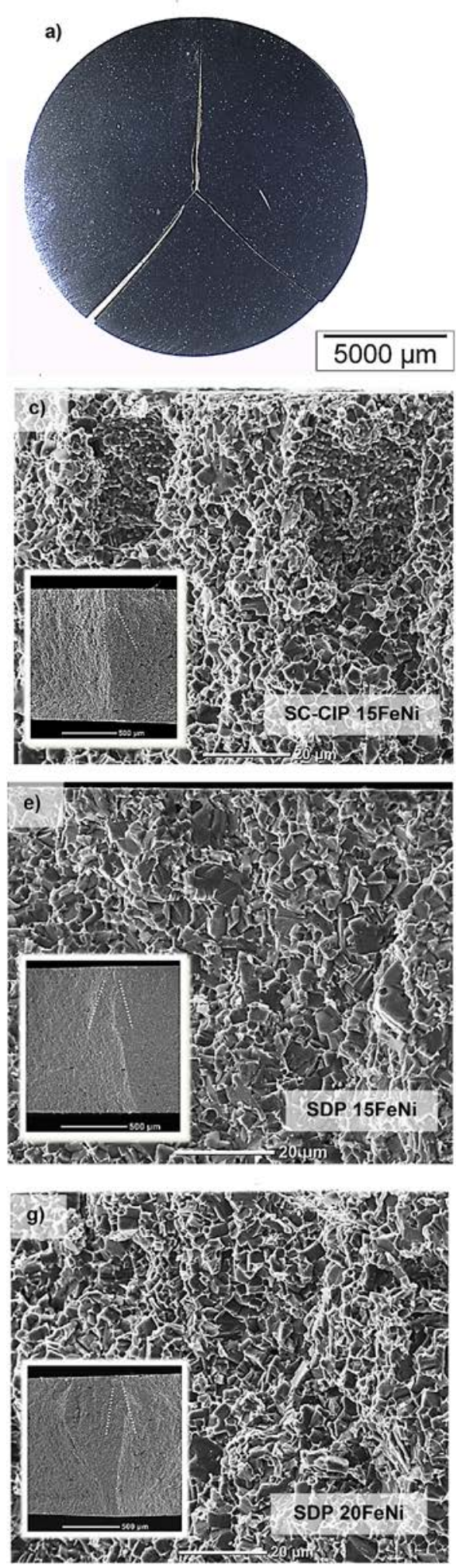
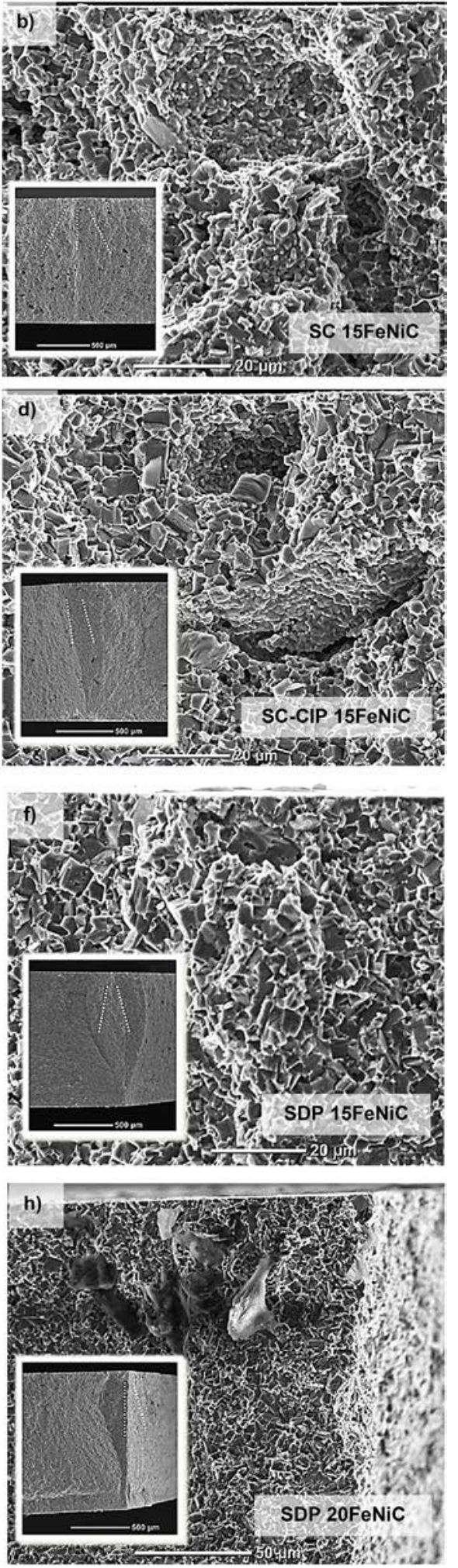

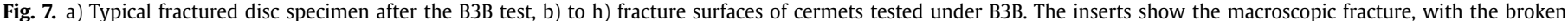
(white) lines pointing toward the fracture origin.

through the ceramic/metal interface while retaining the hardness [30]. As reported in measurements of biaxial resistance, the addi tion of carbon causes a slight modification related to the strengthening of the ceramic/metal interface, as it happens in the case of the SDP 20FeNi materials ( 1530 MPa without carbon and $\sim 1870 \mathrm{MPa}$ with carbon addition). These results are in agreement with that reported by Alvaredo et al. [51] in which a thermody namic simulation using ThermoCalc software was done to calculate 
Table 6

Fracture toughness and work of fracture of the SDP samples.

\begin{tabular}{|c|c|c|c|c|c|}
\hline Sample & $\begin{array}{l}\text { Grain Size } \\
(\mu \mathrm{m})\end{array}$ & $\begin{array}{l}\text { Mean Free path } \\
(\mu \mathrm{m})\end{array}$ & Contiguity & Fracture toughness $\mathrm{K}_{\mathrm{Ic}}\left[\mathrm{MPa} \mathrm{m}{ }^{1 / 2}\right]$ & $\begin{array}{l}\text { Work of fracture } \\
\gamma_{\text {WoF }}\left[\mathrm{J} / \mathrm{m}^{2}\right]\end{array}$ \\
\hline $15 \mathrm{FeNi}$ & $2.21 \pm 0.3$ & $0.74 \pm 0.09$ & 0.470 & $12.2 \pm 0.3$ & $1514 \pm 241$ \\
\hline 15FeNiC & $2.30 \pm 0.2$ & $0.76 \pm 0.06$ & 0.470 & $11.9 \pm 0.4$ & $1314 \pm 115$ \\
\hline $20 \mathrm{FeNi}$ & $2.23 \pm 0.3$ & $0.95 \pm 0.12$ & 0.413 & $13.5 \pm 0.4$ & $1584 \pm 251$ \\
\hline 20FeNiC & $2.19 \pm 0.3$ & $0.93 \pm 0.13$ & 0.413 & $13.8 \pm 0.2$ & $1720 \pm 105$ \\
\hline
\end{tabular}

a)

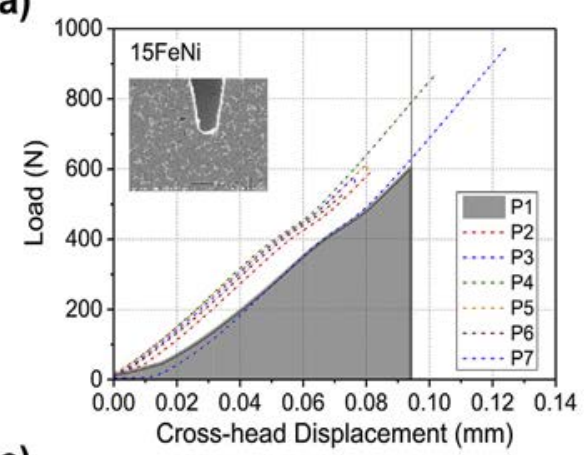

c)

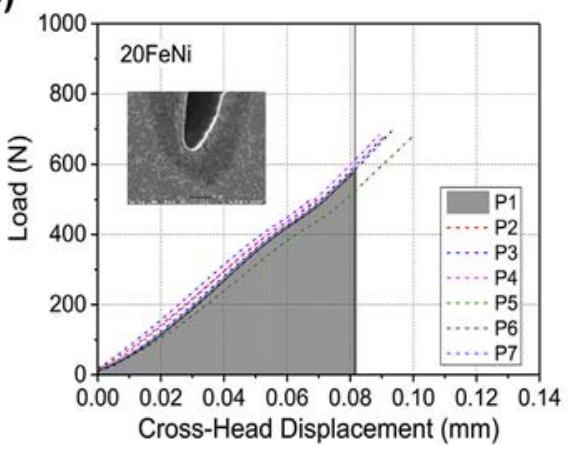

b)

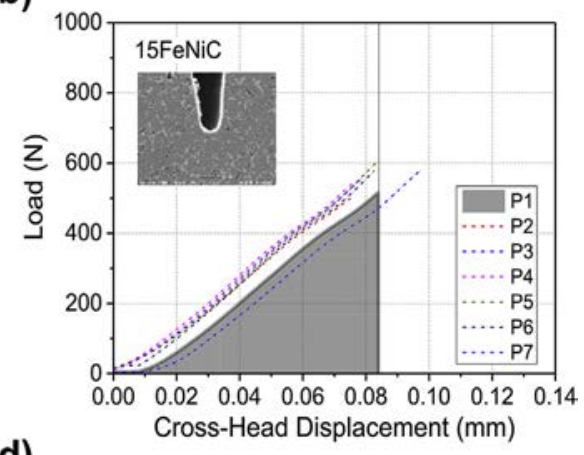

d)

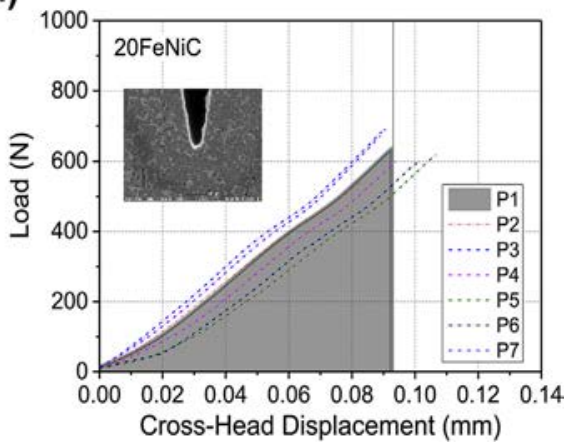

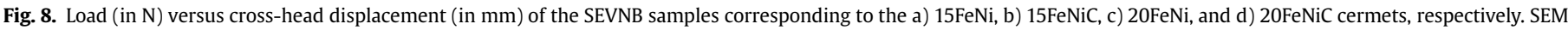
micrographs of the $\mathrm{K}_{\mathrm{Ic}}$ notches are plotted for illustrative purposes. The shadow area in one of the specimens is used to calculate the work-of-fracture.

the effect of carbon additions in the phase diagram of $\mathrm{Ti}(\mathrm{C}, \mathrm{N}) \mathrm{Fe}$ cermets. The results obtained showed a significant influence of the carbon percentage on the solidus temperature, which in fluences sintering behavior, leading to changes in the $\operatorname{Ti}(C, N)$ par ticles shape and composition, due to changes in the stoichiometry of the $\operatorname{Ti}(\mathrm{C}, \mathrm{N})$. The experimental results obtained in this work constitute proof evidence that the appropriate carbon addition to cermet compositions is to be reflected in the cermet microstructure and mechanical properties.

Based on the hardness values [30], strength results and fracture resistance behavior ( $\mathrm{K}_{\mathrm{Ic}}$ and $\left.\gamma_{\mathrm{WOF}}\right)$ supported by the crack paths observed on the fractured specimens, it can be concluded that SDP $20 \mathrm{FeNiC}$ specimens formulated with $0.5 \mathrm{wt} \%$ of carbon are good candidates to improve the mechanical behavior of $\mathrm{Ti}(\mathrm{C}, \mathrm{N})$ based cermets.

\section{Conclusions}

$\mathrm{Ti}(\mathrm{C}, \mathrm{N}) \mathrm{FeNi}$ cermets with different compositions were pre pared combining powder metallurgy and colloidal techniques, to investigate the influence of the processing route, the ceramic/metal balance and the carbon addition on the mechanical properties. The major conclusions are summarized as follows:
+ Considerably improved biaxial strength was observed in the samples obtained through SDP when compared to other tech niques such as SC and SC CIP, due to the increase of density of sintered specimens (from $92.2 \%$ to $99.0 \%$ ). Comparing the biaxial strength of the different cermets investigated, it was found that the difference in strength is determined by the remnant porosity obtained depending on the processing method.

+ The addition of a higher amount of metal binder (from $15 \mathrm{vol} \%$ to 20 vol\%) improved the biaxial strength (from $\sim 1530$ to $\sim 1870 \mathrm{MPa}$ with carbon addition)

+ The effects of the addition of carbon on the mechanical prop erties of sintered $\mathrm{Ti}(\mathrm{C}, \mathrm{N})$ cermets were also investigated. The addition of $0.5 \mathrm{wt} \%$ of carbon with respect to the weight of matrix enhances the rearrangement of $\operatorname{Ti}(\mathrm{C}, \mathrm{N})$ particles during liquid phase sintering and then their densification after the thermal process. The designed cermet processing and formu lation generates a homogeneous distribution of $\mathrm{Ti}(\mathrm{C}, \mathrm{N})$ within the microstructure, which promotes the trans granular fracture of the specimens. The addition of carbon increases the fracture toughness, being this effect more evident in the cermets pro cessed with a higher proportion of metal binder (20FeNiC).

+ The SDP 20FeNiC cermet exhibits enhanced mechanical prop erties with a biaxial strength of 1867 [1832-1903] MPa, a frac ture toughness of $13.8 \pm 0.2 \mathrm{MPa} \mathrm{m} \mathrm{m}^{1 / 2}$ and a work of fracture of 

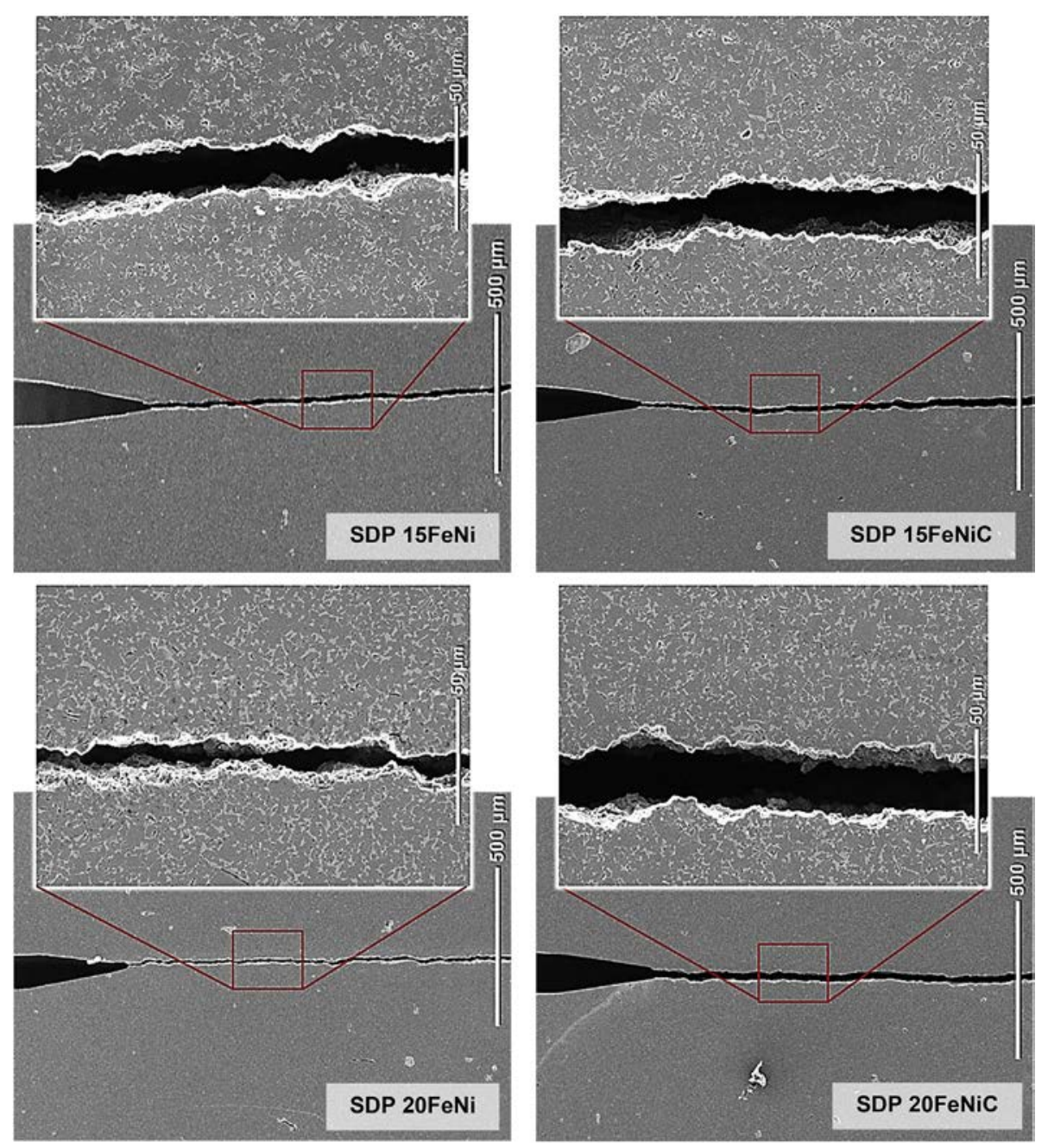

Fig. 9. Macroscopic crack propagation during bending on SEVNB specimens corresponding to SDP 15FeNi and SDP 20FeNi samples, with and without carbon addition.
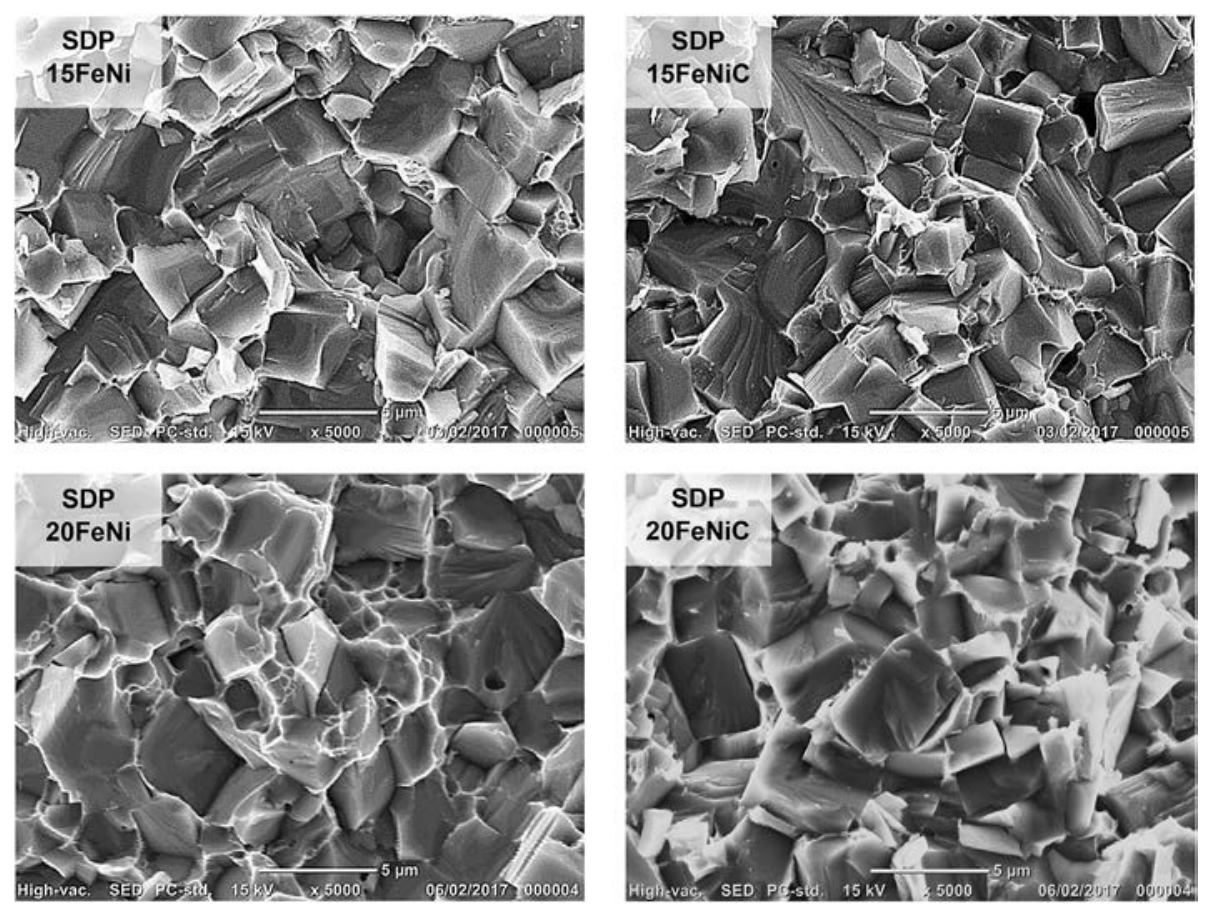

Fig. 10. SEM micrographs of the fracture surfaces of SEVNB SDP samples with different composition: a) $15 \mathrm{FeNi}$, b) $15 \mathrm{FeNiC}$, c) $20 \mathrm{FeNi}$, and d) $20 \mathrm{FeNiC}$, respectively. 
$1720 \pm 105 \mathrm{~J} / \mathrm{m}^{2}$, being the best composite candidates to improve the mechanical performance of the proposed $\mathrm{Ti}(\mathrm{C}, \mathrm{N})$ based cermets meeting the requirements for tool materials. It may be presumed that the ceramic contiguity is deleterious for biaxial strength and fracture toughness of $\mathrm{Ti}(\mathrm{C}, \mathrm{N})$ based cermets.

\section{Acknowledgements}

The authors acknowledge the financial support from the Span ish Government through the projects MAT2015 70780 C4 1 P and MAT2015 70780 C4 2 P, and the Regional Government of Madrid through the program MULTIMAT CHALLENGE, ref. S2013/MIT 2862. M.Dios acknowledges MINECO through the grant BES 2013 065760. I. Kraleva acknowledges financial support by the Austrian Federal Government (in particular from Bundesministerium für Verkehr, Innovation und Technologie and Bundesministerium für Wissenschaft, Forschung und Wirtschaft) represented by Osterreichische Forschungsforderungsgesellschaft $\mathrm{mbH}$ and the Styrian and the Tyrolean Provincial Government, represented by Steirische Wirtschaftsforderungsgesellschaft $\mathrm{mbH}$ and Stand ortagentur Tirol, within the framework of the COMET Funding Programme.

\section{References}

[1] Y. Peng, H. Miao, Z. Peng, Development of TiCN-based cermets: mechanical properties and wear mechanism, Int. J. Refract. Metals Hard Mater. 39 (2013) 78 89, https://doi.org/10.1016/j.ijrmhm.2012.07.001.

[2] A. Rajabi, M.J. Ghazali, J. Syarif, A.R. Daud, Development and application of tool wear: a review of the characterization of TiC-based cermets with different binders, Chem. Eng. J. 255 (2014) 445 452, https://doi.org/10.1016/ j.cej.2014.06.078.

[3] E.T. Jeon, J. Joardar, S. Kang, Microstructure and tribo-mechanical properties of ultrafine $\mathrm{Ti}(\mathrm{CN})$ cermets, Int. J. Refract. Metals Hard Mater. 20 (2002) 207 211, https://doi.org/10.1016/S0263-4368(02)00004-5.

[4] J. Joardar, S.W. Kim, S. Kang, Effect of nanocrystalline binder on the microstructure and mechanical properties of ultrafine $\mathrm{Ti}(\mathrm{CN})$ cermets, Mater. Sci. Eng. A 360 (2003) 385 389, https://doi.org/10.1016/S0921-5093(03)00506-9.

[5] S. Park, S. Kang, Toughened ultra-fine $(\mathrm{Ti}, \mathrm{W})(\mathrm{CN})$ Ni cermets, Scr. Mater 52 (2005) 129 133, https://doi.org/10.1016/j.scriptamat.2004.09.017.

[6] S. Cardinal, A. Malchère, V. Garnier, G. Fantozzi, Microstructure and mechanical properties of TiC-TiN based cermets for tools application, Int. J. Refract. Metals Hard Mater. 27 (2009) 521 527, https://doi.org/10.1016/ j.ijrmhm.2008.10.006.

[7] M. Naidoo, O. Johnson, I. Sigalas, M. Herrmann, Influence of tantalum on the microstructure and properties of $\mathrm{Ti}(\mathrm{C}, \mathrm{N})-\mathrm{Ni}$ cermets, Int. J. Refract. Metals Hard Mater. 42 (2014) 97 102, https://doi.org/10.1016/j.ijrmhm.2013.08.008.

[8] Q. Yang, W. Xiong, M. Zhang, B. Huang, S. Chen, Microstructure and mechanical properties of Mo-free $\mathrm{Ti}(\mathrm{C}, \mathrm{N})$-based cermets with $\mathrm{Ni} \mathrm{xCr}$ binders, $\begin{array}{lllll}\text { J. Alloy. Comp. } 636 & \text { (2015) } 270 \quad 274 \text {, https://doi.org/10.1016/ }\end{array}$ j.jallcom.2014.11.236.

[9] J.M. Córdoba, E. Chicardi, R. Poyato, F.J. Gotor, V. Medri, S. Guicciardi, et al., Spark plasma sintering of TixTa $1-x C 0.5$ N0.5-based cermets: effects of processing conditions on chemistry, microstructure and mechanical properties, Chem. Eng. J. 230 (2013) 558 566, https://doi.org/10.1016/j.cej.2013.06.104.

[10] E. Chicardi, F.J. Gotor, V. Medri, S. Guicciardi, S. Lascano, J.M. Córdoba, Hotpressing of $(\mathrm{Ti}, \mathrm{Mt})(\mathrm{C}, \mathrm{N})$ Co Mo $2 \mathrm{C}(\mathrm{Mt}$ Ta, Nb) powdered cermets synthesized by a mechanically induced self-sustaining reaction, Chem. Eng. J. 292 (2016) 51 61, https://doi.org/10.1016/j.cej.2016.02.007.

[11] Q. Xu, X. Ai, J. Zhao, F. Gong, J. Pang, Y. Wang, Effects of metal binder on the microstructure and mechanical properties of Ti(C,N)-based cermets, J. Alloy. Comp. 644 (2015) 663 672, https://doi.org/10.1016/j.jallcom.2015.05.059.

[12] Q. Xu, X. Ai, J. Zhao, W. Qin, Y. Wang, F. Gong, Comparison of Ti(C,N)-based cermets processed by hot-pressing sintering and conventional pressureless sintering, J. Alloy. Comp. 619 (2015) 538 543, https://doi.org/10.1016/ j.jallcom.2014.08.261.

[13] K. Aigner, W. Lengauer, P. Ettmayer, Interactions in iron-based cermet systems, J. Alloy. Comp. 262263 (1997) 486 491, https://doi.org/10.1016/ S0925-8388(97)00360-5.

[14] E. Gordo, B. Gómez, E.M. Ruiz-Navas, J.M. Torralba, Influence of milling parameters on the manufacturing of Fe-TiCN composite powders, J. Mater. Process. Technol. 162163 (2005) 59 64, https://doi.org/10.1016/ j.jmatprotec.2005.02.154.

[15] B. Gómez, E. Gordo, J.M. Torralba, Influence of milling time on the processing of Fe-TiCN composites, Mater. Sci. Eng. A 430 (2006) 59 63, https://doi.org/ 10.1016/j.msea.2006.05.051.
[16] M. Chen, Q. Zhuang, N. Lin, Y. He, Improvement in microstructure and mechanical properties of $\mathrm{Ti}(\mathrm{C}, \mathrm{N})$-Fe cermets with the carbon additions, J. Alloy. Comp. 701 (2017) 408 415, https://doi.org/10.1016/j.jallcom.2017.01.119.

[17] Z. Guo, J. Xiong, M. Yang, J. Wang, L. Sun, Y. Wu, et al., Microstructure and properties of Ti(C,N) Mo2C Fe cermets, Int. J. Refract. Metals Hard Mater. 27 (2009) 781 783, https://doi.org/10.1016/j.ijrmhm.2009.01.003.

[18] J. Xiong, Z. Guo, B. Shen, D. Cao, The effect of WC, Mo2C, TaC content on the microstructure and properties of ultra-fine TiC0.7N0.3 cermet, Mater. Des. (2007), https://doi.org/10.1016/j.matdes.2006.03.005.

[19] J. Wang, Y. Liu, P. Zhang, J. Ye, M. Tu, Effect of VC and nano-TiC addition on the microstructure and properties of micrometer grade $\mathrm{Ti}(\mathrm{CN})$-based cermets, Mater. Des. 30 (2009) 2222 2226, https://doi.org/10.1016/ j.matdes.2008.08.017.

[20] H. Yu, Y. Liu, Y. Jin, J. Ye, Effect of secondary carbides addition on the microstructure and mechanical properties of $(\mathrm{Ti}, \mathrm{W}, \mathrm{Mo}, \mathrm{V})(\mathrm{C}, \mathrm{N})$-based cermets, Int. J. Refract. Metals Hard Mater. 29 (2011) 586 590, https://doi.org/ 10.1016/j.ijrmhm.2011.03.013.

[21] E. Chicardi, Y. Torres, M.J. Sayagués, V. Medri, C. Melandri, J.M. Córdoba, et al., Toughening of complete solid solution cermets by graphite addition, Chem. Eng. J. 267 (2015) 297 305, https://doi.org/10.1016/j.cej.2015.01.022.

[22] P. Alvaredo, J.J. Roa, E. Jiménez-Pique, L. Llanes, E. Gordo, Characterization of interfaces between TiCN and iron-base binders, Int. J. Refract. Metals Hard Mater. 63 (2017) 32 37, https://doi.org/10.1016/j.ijrmhm.2016.08.010.

[23] S. Acharya, M. Debata, T.S. Acharya, P.P. Acharya, S.K. Singh, Influence of nickel boride addition on sintering behaviour and mechanical properties of TiC N based cermets, J. Alloy. Comp. 685 (2016) 905 912, https://doi.org/10.1016/ j.jallcom.2016.06.122.

[24] G. Liu, J. Li, K. Chen, Combustion synthesis of refractory and hard materials: a review, Int. J. Refract. Metals Hard Mater. 39 (2013) 90 102, https://doi.org/ 10.1016/j.ijrmhm.2012.09.002.

[25] G. Liu, J. Li, K. Chen, One-step preparation of dense TiC1-xNx Ni3Ti cermet by combustion synthesis, Mater. Des. 87 (2015) 6 9, https://doi.org/10.1016/ j.matdes.2015.07.179.

[26] E.A. Levashov, A.S. Mukasyan, A.S. Rogachev, D. V Shtansky, Self-propagating high-temperature synthesis of advanced materials and coatings, Int. Mater Rev. 62 (2017) 203 239, https://doi.org/10.1080/09506608.2016.1243291.

[27] J. Xiong, Z. Guo, M. Yang, B. Shen, Preparation of ultra-fine TiC0.7N0.3-based cermet, Int. J. Refract. Metals Hard Mater. 26 (2008) 212 219, https://doi.org/ 10.1016/j.ijrmhm.2007.05.001

[28] J.A. Escribano, J.L. García, P. Alvaredo, B. Ferrari, E. Gordo, A.J. Sanchez-Herencia, FGM stainless steel-Ti(C,N) cermets through colloidal processing, Int. J. Refract. Metals Hard Mater. 49 (2015) 143 152, https://doi.org/10.1016/ j.ijrmhm.2014.05.008.

[29] M. Dios, Z. Gonzalez, E. Gordo, B. Ferrari, Chemical precipitation of nicke nanoparticles on $\mathrm{Ti}(\mathrm{C}, \mathrm{N})$ suspensions focused on cermet processing, Int. J Refract. Metals Hard Mater. 63 (2017) 2 8, https://doi.org/10.1016/ j.ijrmhm.2016.08.009.

[30] M. Dios, Z. Gonzalez, P. Alvaredo, E. Gordo, R. Bermejo, B. Ferrari, Novel colloidal approach for the microstructural improvement in $\mathrm{Ti}(\mathrm{C}, \mathrm{N}) / \mathrm{FeNi}$ cermets, J. Alloy. Comp. (2017).

[31] R.G. Neves, B. Ferrari, A.J. Sanchez-Herencia, C. Pagnoux, E. Gordo, Role of stabilisers in the design of Ti aqueous suspensions for pressure slip casting Powder Technol. 263 (2014) 81 88, https://doi.org/10.1016/ j.powtec.2014.04.093.

[32] N. Hernández, A.J. Sánchez-Herencia, R. Moreno, Forming of nickel compacts by a colloidal filtration route, Acta Mater. 53 (2005) 919 925, https://doi.org/ 10.1016/j.actamat.2004.10.038.

[33] Z. Guo, J. Xiong, M. Yang, S. Xiong, J. Chen, Y. Wu, et al., Dispersion of nano-TiN powder in aqueous media, J. Alloy. Comp. 493 (2010) 362 367, https:/ doi.org/10.1016/j.jallcom.2009.12.103.

[34] M. Dios, Z. Gonzalez, P. Alvaredo, E. Gordo, R. Bermejo, B. Ferrari, Novel colloidal approach for the microstructural improvement in $\mathrm{Ti}(\mathrm{C}, \mathrm{N}) / \mathrm{FeNi}$ cermets, J. Alloy. Comp. 724 (2017) 327 338, https://doi.org/10.1016/ j.jallcom.2017.07.034.

[35] B. Roebuck, E.A. Almond, Deformation and fracture processes and the physical metallurgy of WC Co hardmetals, Int. Mater. Rev. 33 (1988) 90 112, https:/ doi.org/10.1179/imr.1988.33.1.90.

[36] R.K. Viswanadham, T.S. Sun, E.F. Drake, J.A. Peck, Quantitative fractography of WC-Co cermets by Auger spectroscopy, J. Mater. Sci. 16 (1981) 10291038 https://doi.org/10.1007/BF00542749.

[37] Y. Torres, Comportamiento a fractura y fatiga de carburos cementados WC Co, Universidad Politécnica de Cataluna, 2002.

[38] D. Coureaux, Comportamiento mecánico de carburos cemen-tados WC Co: influencia de la microestructura en la resistencia a la fractura, la sensibilidad a la fatiga y la tolerancia al dano inducido bajo solicitaciones de contacto, Universidad Politécnica de Cataluna, 2012.

[39] A. Borger, P. Supancic, R. Danzer, The ball on three balls test for strength testing of brittle discs: stress distribution in the disc, J. Eur. Ceram. Soc. 22 (2002) 1425 1436, https://doi.org/10.1016/S0955-2219(01)00458-7.

[40] A. Borger, P. Supancic, R. Danzer, The ball on three balls test for strength testing of brittle discs: Part II: analysis of possible errors in the strength determination, J. Eur. Ceram. Soc. 24 (2004) 2917 2928, https://doi.org 10.1016/j.jeurceramsoc.2003.10.035.

[41] R. Danzer, W. Harrer, P. Supancic, T. Lube, Z. Wang, A. Borger, The ball on three balls test strength and failure analysis of different materials, J. Eur. Ceram. 
Soc. $27 \quad(2007) \quad 1481$ 1485, https://doi.org/10.1016/ j.jeurceramsoc.2006.05.034

[42] Y. Torres, R. Bermejo, F.J. Gotor, E. Chicardi, L. Llanes, Analysis on the mechanical strength of WC-Co cemented carbides under uniaxial and biaxia bending, Mater. Des. 55 (2014) 851 856, https://doi.org/10.1016 j.matdes.2013.10.051.

[43] R. Bermejo, R. Danzer, 2.09 mechanical characterization of ceramics: designing with brittle materials, Compr. Hard Mater (2014) 285 298, https:// doi.org/10.1016/B978-0-08-096527-7.00028-3.

[44] R. Bermejo, P. Supancic, R. Danzer, Influence of measurement uncertainties on the determination of the Weibull distribution, J. Eur. Ceram. Soc. 32 (2012) 251 255, https://doi.org/10.1016/J.Jeurceramsoc.2011.09.008.

[45] M. Deluca, R. Bermejo, M. Pletz, P. Supancic, R. Danzer, Strength and fracture analysis of silicon-based components for embedding, J. Eur. Ceram. Soc. 31 (2011) 549 558, https://doi.org/10.1016/j.jeurceramsoc.2010.10.029.

[46] R. Damani, R Gstrein, R Danzer, Critical notch-root radius effect in SENB-S fracture toughness testing. J. Eur. Ceram. Soc. 16 (1996) 695 702, https:/ doi.org/10.1016/0955-2219(95)00197-2.
[47] ENV 843-1 Advanced Technical Ceramics Monolithic Ceramics Mechanical Tests at Room Temperature Part 1: Determination of Flexural Strength, 1995 (n.d.).

[48] ISO/DIS 23146 Fine Ceramics (Advanced Ceramics, Advanced Technical Ceramics) Test Methods for Fracture Toughness of Monolithic Ceramics Single-edge V-notch Beam (SEVNB) Method, 2007 (n.d.).

[49] H.G. Tattersall, G. Tappin, The work of fracture and its measurement in metals, ceramics and other materials, J. Mater. Sci. 1 (1966) 296 301, https://doi.org/ 10.1007/BF00550177.

[50] E. Chicardi, Y. Torres, J.M. Córdoba, M.J. Sayagués, J. a. Rodríguez, F.J. Gotor, Effect of sintering time on the microstructure and mechanical properties of $(\mathrm{Ti}, \mathrm{Ta})(\mathrm{C}, \mathrm{N})$-based cermets, Int. J. Refract. Metals Hard Mater. 38 (2013) 73 80, https://doi.org/10.1016/j.ijrmhm.2013.01.001.

[51] P. Alvaredo, S.A. Tsipas, E. Gordo, Influence of carbon content on the sinterability of an FeCr matrix cermet reinforced with TiCN, Int. J. Refract. Metals Hard Mater. 36 (2013) 283 288, https://doi.org/10.1016/ 